\title{
Good fences make good neighbors: Collaborating with families to create employment opportunity
}

\author{
Bethany Chase* \\ Rutgers University, The Boggs Center on Developmental Disabilities, New Brunswick, NJ, USA
}

Received 1 December 2020

Accepted 1 December 2020

\begin{abstract}
.
BACKGROUND: Collaboration between supported employment providers and parents/guardians of job seekers with intellectual and/or developmental disabilities is key to employment success. However, parents are often concerned about the efficacy of employment supports or the capacity of the professionals providing the service. Likewise, job coaches may consider certain kinds of parent involvement as detrimental to a successful job match.

OBJECTIVE: This article provides context for why parents/guardians may be distrustful of the employment process, as well as why employment specialists may struggle to build strong partnerships with parents/guardians.

METHODS: This article will discuss how to implement practices that not only welcome the critical input of families, but also maintain healthy and well-defined boundaries that affirm the autonomy, professionalism, and competence of the worker.
\end{abstract}

Keywords: Supported employment, employment specialist, parent involvement, parent collaboration

\section{Background}

High parent/guardian expectations are one of the strongest indicators for employment success for individuals with intellectual and/or developmental disabilities (IDD) (Carter et al., 2012; Francis et al., 2015; Kramer et al., 2017; Lindstrom et al., 2007). Parents have a powerful role to play in their adult child's career development and in the formation of a positive work ethic (Dixon \& Reddacliff, 2001; Kramer et al., 2017; Lindstrom et al., 2007). During the vocational assessment, parents can offer critical information regarding their adult child's strengths,

\footnotetext{
*Address for correspondence: Bethany Chase, Rutgers University, The Boggs Center on Developmental Disabilities, 335 George St, New Brunswick, NJ, USA. Tel.: +1 732235 9316; E-mail: Bethany.Chase@Rutgers.edu.
}

skills, challenges, and support needs (Timmons \& Wolfe, 2011). They can provide insight on goals, communication preferences, learning strategies, and on what makes their child feel motivated and confident (Duvdevany, 2001). Further, parents may have social capital that they can leverage to assist in the job search and job development process (Duvdevany, 2001). For example, many will have networks that include friends, coworkers, those with whom they worship, volunteer, or engage with in community activities. These connections are often helpful in opening doors and finding opportunities.

There is no question that parents and guardians are a powerful force for employment for individuals with IDD, and as a result, it is in the best interest of any supported employment agency to harness that power. Consequently, one might deduce that parent involvement in the employment process is generally 
welcome, seamless, and positive for all involved. But in reality, it is often not that simple. Employment specialists frequently perceive the parent as intruding on their efforts to secure and maintain an appropriate job match, while parents tend to believe that the professionals want too much control and influence. The job seeker, meanwhile, may feel disempowered as the two other parties engage in a struggle for control (Cooney, 2002).

\section{Objective}

Without understanding parental experiences interacting with adult service providers, professionals may struggle to develop an effective supported employment program (Duvdevany, 2001). The objective of this article is to outline common reasons why positive, collaborative partnerships between parents and employment specialists may be difficult to maintain, and how that conflict not only overshadows the autonomy and agency of the job seeker, but also negatively affects employment outcomes. This article provides supported employment professionals with suggestions, tips, and solutions that will lead to positive parent/guardian engagement defined by clear expectations and mutually beneficial boundaries that center the self-determination and the career of the job seeker.

\section{Method}

The Boggs Center on Developmental Disabilities at Rutgers University is New Jersey's federally designated University Center for Excellence in Developmental Disabilities. Instructors at The Boggs Center conduct on-going, 4-day Employment Specialist Foundations courses, which provide training to employment specialists and other professionals in the field regarding best practices in supported employment. In 2020, The Boggs Center hosted approximately 400 professionals in their Employment Specialist Foundations trainings. In these courses, employment specialists frequently asked questions regarding parent/guardian involvement, and over the course of the year, consistent challenges and themes emerged. This article first synthesizes these concerns, and then offers evidence from the literature that corroborates the universality of these challenges. Next, it provides a review of the literature regarding the barriers that parents experience when engaging with adult service providers, and specifically, with employment services. Finally, it offers practice recommendations and solutions that promote collaborative partnerships with families based on best practices within the field of supported employment.

\section{Results}

\subsection{The employment specialist perspective}

Supported employment professionals have reason for reservations about parent involvement. Many have experienced parents as a barrier to employment, rather than an asset to the process (Hall et al., 2014; Kramer et al., 2020). For example, a parent may be highly risk averse and question their child's employment potential, resulting in ambivalence about employment (Dixon \& Reddacliff, 2001). They may also not appreciate the value of employment beyond the paycheck, citing their own willingness to take care of their child financially and/or choosing instead to prioritize social security benefits over paid employment (Kramer et al., 2020). Additionally, parents and their adult children do not always share a vision for employment (Cooney, 2002), and as a result, parents may attempt to prioritize their own ideas at the expense of their child's goals (Hall et al., 2014).

Dixon and Reddacliff (2001) performed a qualitative research study involving 15 young adults and their families, all of whom were engaged with supported employment services. In the semi-structured interviews, parents reported a range of concerns about their child's employment experience, including what they perceived as unrealistic performance expectations, unacceptable scheduling, unfair termination, concern about their child's relationships with coworkers and supervisors, and overall suspicion of employment discrimination due to disability. Further, rather than approaching the employment specialist to discuss these concerns, parents reported that they self-initiated contact with the employer directly (Dixon \& Reddacliff, 2001). While their concerns may indeed be valid and justify action, parents who approach their adult child's supervisor directly will undermine their child's autonomy, professionalism, the work of the employment specialist, and may put the overall job into jeopardy.

The following table (Table 1) outlines further common barriers to effective parent/professional collaboration discussed by employment specialists during Employment Specialist Foundations courses at The Boggs Center. 
Table 1

\begin{tabular}{ll}
\hline $\begin{array}{l}\text { Repeatedly dropping by employment site } \\
\text { unannounced }\end{array}$ & $\begin{array}{c}\text { Prioritizing social security benefits over } \\
\text { employment checks, thus prohibiting or } \\
\text { limiting employment }\end{array}$ \\
\hline $\begin{array}{l}\text { Having expectations that the job coach and } \\
\text { support team believed were unattainable at that } \\
\text { time, due to the job seeker lacking appropriate } \\
\text { skills/needing additional experience/training }\end{array}$ & $\begin{array}{l}\text { Having a different opinion than their adult child } \\
\text { on an appropriate career goal, and insisting the } \\
\text { job coach prioritize their opinion }\end{array}$ \\
$\begin{array}{l}\text { Having expectations that the job coach believed } \\
\text { were too low, prohibiting career placement, } \\
\text { advancement, or growth }\end{array}$ & $\begin{array}{l}\text { Belief that an employment specialist's job is to } \\
\text { curate the specific job requested, while the job } \\
\text { seeker simply waits to be told when and where } \\
\text { to show up for their first day }\end{array}$ \\
\hline $\begin{array}{l}\text { Approaching/contacting employer directly to } \\
\text { discuss issues with their adult child's } \\
\text { employment }\end{array}$ & $\begin{array}{l}\text { Parent calling out sick, requesting time off, etc. } \\
\text { for their adult child, rather than supporting } \\
\text { their child to do it themselves, in spite of the } \\
\text { worker being able to do so }\end{array}$ \\
\hline
\end{tabular}

\subsection{The parent/guardian perspective}

There is a rich body of research demonstrating that parents/guardians experience the adult service system as a source of stress, frustration, and anxiety (Ferguson \& Ferguson, 1993; Lustig \& Thomas, 1997; Timmons et al., 2004). Families are often looking for a genuine connection with a professional they can trust. Meanwhile, professionals often adapt an overly "expert/client" dynamic, which can result in families feeling unseen and the supports viewed as unsuitable to meet their adult child's needs (Cooney, 2002). Ferguson \& Ferguson (1993) describe a phenomenon they call "professional preciousness," whereby professionals fail to assess the needs of an individual with IDD objectively, and instead define the needs in a way that requires an "expert," (i.e. themselves) as the only way to solve the problem. In other words, the providers define the needs simply by what they happen to be able to provide.

Utilizing case studies and focus groups, Timmons et al. (2004) gathered information from 30 parents of young adults with I/DD in order to learn more about their experiences navigating and interacting with the adult service system. Their overall findings revealed that parents had difficulty learning about, navigating, and accessing support options. When they finally did secure a program, parents reported that these supports and services were unreliable. Parents characterized the adult system as "complex, inconsistent, and unresponsive" (pg. 20). They reported ongoing difficulty getting their concerns addressed, citing a regular occurrence of waiting, sometimes indefinitely, to have a phone call or email returned (Cooney, 2002). While parents did express positive experiences with specific professionals, parents suspected that finding this person was nothing more than "luck," and therefore, continued to experience uncertainty, knowing the person could leave their position at any time (Timmons et al., 2004). A parent interviewed in the qualitative study by Kramer et al. (2020) summed it up by saying, "I am also becoming more and more doubtful that our continued rage at an unfair and largely inaccessible system for people with intellectual disabilities will ever result in what we want and need" (p. 321).

When considering employment supports specifically, parents often experience a great deal of anxiety about the ability of an individual or a system to appropriately support a successful employment opportunity for their adult child. Concerns include worrying that supervisors and coworkers will not be tolerant and kind (Lustig \& Thomas, 1997), that their child will be exploited by an employer (Dixon \& Reddacliff, 2001), and that professionals will overlook their child's capacities and focus exclusively on their limitations and barriers to employment (Taub, 2006). Parents have observed that vocational assessments often do not reflect the skills and career goals of their child, and suspect that employment professionals are more concerned with placing their child and quickly closing the case than they are with finding the right job fit (Kramer et al., 2020).

With these concerns in mind, it is not difficult to see why some parents/guardians would be distrustful of the supported employment process, and why they may feel the need to intervene. Parents often are tasked with juggling and navigating the systems that affect their child academically, vocationally, and medically. Many see their role as the "linchpin" (Timmons et al., 2004, pg. 23) in the wheel making their child's life work; thus, should they step aside, they 
fear that all of the systems and supports will fall apart (Timmons et al., 2004).

\subsection{Strategies to building effective partnerships}

While these perspectives may at first seem poles apart, there is much that an employment specialist can do to bridge the gap. There is, in fact, much common ground upon which to build effective partnership. Both sides wish for an effective process with clear roles, firm boundaries, and accountability that results in long term employment success for the individual with IDD. The following are intervention tips and strategies that employment agencies can utilize to promote effective partnerships with families.

\subsection{Intervention Strategies}

\subsubsection{Create a supported employment parent handbook}

Parents consistently state that a lack of information from providers is a primary source of stress and frustration (Duvdevany, 2001; Lindstrom et al., 2007; Timmons et al., 2004). Therefore, proactive and clear communication is one of the most effective ways to build positive relationships. The creation of a parent handbook can be a helpful way to communicate expectations and guideposts for a positive, collaborative relationship (Timmons et al., 2004). Employment specialists should consider the following in the creation of a parent handbook:

4.4.1.1 Speak human, not human service. The purpose of this handbook is not to outline jargon, acronyms, billing/legal procedures, etc. While these are also helpful to have in writing, the objective of this particular document is to communicate in a less formal manner how services will take place, what your responsibility and commitment is to the job seeker, and when and how family/parent involvement is welcome. The writing should be kind, compassionate, accessible, and welcoming.

4.4.1.2 Acknowledge and validate common questions, concerns, and fears. Demonstrate to parents that you are aware of common parent concerns, and as a result, you have established solutions. Affirm your dedication to the belief that all individuals with disabilities can work, and describe how your agency has successfully supported individuals who exhibit a wide range of support needs. Consider including content such as how coworker/supervisor relationships are built and monitored, what job coaching strategies you may use, how your agency identifies problems, and what the process is for intervening. Acknowledge the frustration of unreturned phone calls, affirm your commitment to open communication, and clarify the usual wait-time for a return phone call or email.

\subsubsection{Outline options for positive and appropriate} participation. Outline the role for parents, guardians, and family members in the employment process. Describe their involvement in person-centered planning activities and in the creation of the vocational profile. Be sure to explain that while their input is incredibly important, your ultimate shared goal will be to center and prioritize the voice of the job seeker.

Discuss how most job seekers leverage their social networks when job hunting, and thus, parent contacts are welcome. Explain how your agency follows up with potential job leads and suggestions. Be clear, however, that once the contact is shared, the communication moving forward will not involve the parent. This is to professionalize the process and center the job seeker, as parents typically do not assist their adult children in employment negotiations. Make sure to clarify that if the job leads are not of interest to the job seeker, that you will not be pursuing them as a potential job placement. Remind them this is because you share the objective of self-determination and longterm employment success for their child.

4.4.1.4 Explain what kinds of involvement is not helpful to the process. In addition to explaining how and when their input will be welcomed, explain what kinds of parent involvement is detrimental to their child's employment success. Ask parents not to stop by the employment site or contact the employer/ supervisor directly. Confirm that the employment vision of the job seeker will always take center stage, even if the parent does not fully agree with their child's career goals. Often times, encouraging families to first reflect on what they would and would not like their own family members to do (such as dictating what career they should pursue or regularly stopping by the job to check on them) is enough for many to realize when they need to hold back.

4.4.1.5 Have the introduction come from a parent. Consider asking a parent with whom you have a good working relationship to write the introduction in the handbook, speaking directly to fellow parents about the challenges and rewards of the process, and the efficacy and reliability of your organization. 


\subsubsection{Get approval for the handbook from a parent/} self-advocate focus group. Before publishing and disseminating, ensure that a group of parents and self-advocates has read the handbook and has given feedback. Ensure that the self-advocates agree that the content centers their own autonomy and agency, and describes the kind of support they would like from their parents/guardians. The group should agree that the handbook is clear, positive, and welcoming, and that you were effective in describing appropriate roles and boundaries in a collaborative way.

\subsubsection{Create a family action committee}

A family action committee can mobilize and organize motivated parents who wish to be further involved in promoting and advocating employment for all people with IDD in your community. This committee can leverage their own networking power to connect with local community leaders, major employers, and small businesses to foster a larger network of employers who affirm the benefits of hiring individuals with IDD, and specifically, with working with your agency. Parents on such a committee can also fundraise, and/or host events and other activities. Parent committees can be an excellent way to advance your agency and also provide a sense of partnership and community for the families you serve.

\section{Conclusion}

It is often said that good fences make good neighbors. Parent expectations, input, and support is vital to employment success for individuals with IDD. By setting proactive, positive, welcoming, and compassionate guidelines and boundaries, employment specialists can reap the benefits of an engaged family while continuing to affirm the professionalism, autonomy, and competence of the worker.

\section{Conflict of interest}

None to report.

\section{References}

Carter, E. W., Austin, D., \& Trainor, A. A. (2012). Predictors of postschool employment outcomes for young adults with severe disabilities. Journal of Disability Policy Studies, 23(1), 50-63. https://doi.org/10.1177/1044207311414680
Cooney, B. F. (2002). Exploring perspectives on transition of youth with disabilities: Voices of young adults, parents, and professionals. Mental Retardation, 40(6), 425-435. https:// doi.org/10.1352/0047-6765(2002)040<0425:EPOTOY>2.0. $\mathrm{CO} ; 2$

Dixon, R. M., \& Reddacliff, C. A. (2001). Family contribution to the vocational lives of vocationally competent young adults with intellectual disabilities. International Journal of Disability, Development and Education, 48(2), 193-206. https://doi.org/10.1080/10349120120053667

Duvdevany, I. (2001). Parents of adult children with developmental disabilities: stress, social support and their views of normalization in relation to their attitudes toward their children's employment. International Journal of Rehabilitation Research, 24(3), 227-232. https://doi.org/10.1097/00004356200109000-00008

Ferguson, P. M., \& Ferguson, D. L. (1993). The promise of adulthood. In M. E. Snell (Ed.), Instruction of students with severe disabilities (4th ed.; pp. 588-607). Macmillan.

Francis, G. L., Gross, J. M., Turnbull, A. P., \& Turnbull III, H. R. (2015). An exploratory investigation into family perspectives after the family employment awareness training. Career Development and Transition for Exceptional Individuals, 38(2), 68-77. https://doi.org/10.1177/2165143414528241

Hall, A., Bose, J., Winsor, J., \& Migliore, A. (2014). Knowledge translation in job development: Strategies for involving families. Journal of Applied Research in Intellectual Disabilities, 27(5), 489-492. https://doi.org/10.1111/jar.12077

Kramer, J., Bose, J., \& Shepard, J. (2017). Beyond training: Engaging families in the transition to employment. Bringing employment first to scale, Issue No. 12. Institute for Community Inclusion.

Kramer, J., Bose, J., Shepard, J., \& Winsor, J. (2020). Engaging families in employment: Individuals and families' retrospective transition experiences with employment services. Intellectual and Developmental Disabilities, 58(4), 314-327. https://doi.org/10.1352/1934-9556-58.4.314

Lindstrom, L., Doren, B., Metheny, J., Johnson, P., \& Zane, C. (2007). Transition to employment: Role of the family in career development. Exceptional Children, 73(3), 348-366. https://doi.org/10.1177/001440290707300305

Lustig, D., \& Thomas, K. (1997). Adaptation of families to the entry of young adults with mental retardation into supported employment. Education and Training in Mental Retardation and Developmental Disabilities, 21-31.

Taub, D. J. (2006). Understanding the concerns of parents of students with disabilities: Challenges and roles for school counselors. Professional School Counseling, 10(1). https://doiorg.proxy.libraries.rutgers.edu/10.1177/2156759X0601001S07

Timmons, J. C., Whitney-Thomas, J., McIntyre Jr, J. P., Butterworth, J., \& Allen, D. (2004). Managing service delivery systems and the role of parents during their children's transitions. Journal of Rehabilitation, 70(2), 19.

Timmons, J., \& Wolfe, A. (2011). The influential role of the job developer: Increasing self-determination and family involvement during the job search. Research to Practice Brief, 49, $1-4$. 